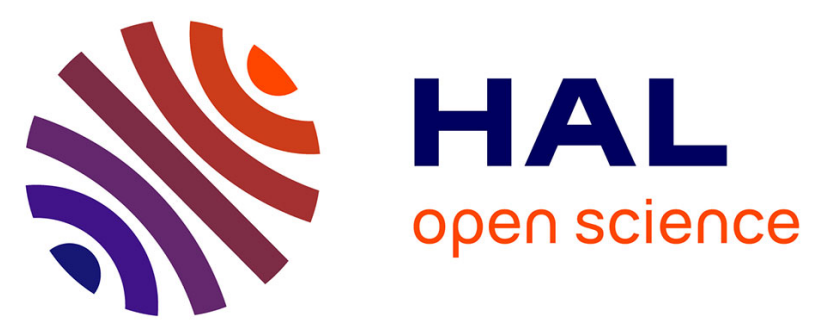

\title{
Formation of Hexagonal Ferrite Particles from the Disordered Fe2O3-BaO-B2-O3 System
}

M. Nejezchleba, A. Klarikova, J. Subrt, V. Stengl, K. Zaveta, M. Marysko

\section{To cite this version:}

M. Nejezchleba, A. Klarikova, J. Subrt, V. Stengl, K. Zaveta, et al.. Formation of Hexagonal Ferrite Particles from the Disordered Fe2O3-BaO-B2-O3 System. Journal de Physique IV Proceedings, 1997, 07 (C1), pp.C1-537-C1-538. 10.1051/jp4:19971220 . jpa-00254893

\section{HAL Id: jpa-00254893 https://hal.science/jpa-00254893}

Submitted on 1 Jan 1997

HAL is a multi-disciplinary open access archive for the deposit and dissemination of scientific research documents, whether they are published or not. The documents may come from teaching and research institutions in France or abroad, or from public or private research centers.
L'archive ouverte pluridisciplinaire HAL, est destinée au dépôt et à la diffusion de documents scientifiques de niveau recherche, publiés ou non, émanant des établissements d'enseignement et de recherche français ou étrangers, des laboratoires publics ou privés. 


\title{
Formation of Hexagonal Ferrite Particles from the Disordered $\mathrm{Fe}_{2} \mathrm{O}_{3}-\mathrm{BaO}-\mathrm{B}_{2}-\mathrm{O}_{3}$ System
}

\author{
M. Nejezchleba, A. Klarikova, J. Subrt*, V. Steng1*, K. Zaveta** and M. Marysko** \\ Joint Laboratory of Mössbauer Spectroscopy, KFNT - MFF UK, V Holesovickach 2, 18000 Praha 8, \\ Czech Republic \\ * Institute of Inorganic Chemistry, UACH AVCR, Pelléova 24, 16000 Praha 6, Czech Republic \\ ** Institute of Physics, FzU AVCR, Cukrovarnicka 10, 16200 Praha 6, Czech Republic
}

\begin{abstract}
It was shown that by high energy milling and subsequent annealing of the disordered powders from the $\mathrm{BaO}-\mathrm{Fe}_{2} \mathrm{O}_{3}$ $-\mathrm{B}_{2} \mathrm{O}_{3}$ system crystalline particles of hexagonal barium ferrite are produced, whose formation commences slightly above 700 and is practically completed at about $800^{\circ} \mathrm{C}$. Both the $\mathrm{X}$-ray diffraction and Mossbauer spectroscopy confirmed that the ensuing phase possesses the magnetoplumbite structure and its relative amount increases with the annealing temperature and/or time at the expense of the ferric oxide. These data are in reasonably good quantitative agreement with the results of the measurements of the magnetic moment of the particle systems.
\end{abstract}

\section{INTRODUCTION}

Hexagonal barium ferrites have been well known materials for permanent magnets for several decades. Renewed attention to them was stimulated by their possible exploitation in magnetic perpendicular recording [1]. For this purpose, however, particles with strictly defined magnetic parameters, as well as size and shape distributions, are needed which in turn requires special technological approach. The method of glass crystallisation [2] consists in melting the proper amounts of the oxides with a glass -forming component, rapid quenching of the melt, controlled crystallisation of the resulting glass and finally chemical separation of the unwanted components. The particles produced by this method satisfy much better the stringent requirements than the powders made by crushing and milling the polycrystalline materials manufactured by the usual ceramic way of preparation.

In the present work we study the formation and properties of particle systems produced by high-energy milling of proper ratios of $\mathrm{BaCO}_{3}, \mathrm{Fe}_{2} \mathrm{O}_{3}$, and $\mathrm{H}_{3} \mathrm{BO}_{3}$ in a planetary mill followed by annealing the highly deformed powders at temperatures of $700-800{ }^{\circ} \mathrm{C}$. This method of preparation combines the advantageous features of the two above mentioned procedures.

\section{EXPERIMENTAL}

\subsection{Technology and characterisation of samples}

The molar ratios of $38.8 \mathrm{BaCO}_{3}-30 \mathrm{Fe}_{2} \mathrm{O}_{3}-31.2 \mathrm{H}_{3} \mathrm{BO}_{3}$ were ground in the planetary mill for 2 hours, some series of the mixed precursors were processed by high power ultrasound with up to $100 \mathrm{~W} / \mathrm{cm}^{2}$. After annealing at $700-800{ }^{\circ} \mathrm{C}$ for $60 \mathrm{~min}$ the unwanted components were etched off by acetic acid. The powders were observed in TEM and found to contain relatively narrow distribution of particle sizes on the order of 0.1 to $1 \mu \mathrm{m}$. X-ray diffraction confirmed that the product contains barium hexaferrite of the $\mathrm{M}$ structure $(\mathrm{BaM})$, whose amount increases with both the annealing temperature and time.

The magnetic moments per unit mass (specific magnetisation $\sigma$ ) were measured at 10 and $300 \mathrm{~K}$ in magnetic fields up to $5 \mathrm{~T}$ by means of a SQUID magnetometer. The values of remanent magnetisation indicate that the BaM crystals in the powder are randomly oriented.

\section{2 Mössbauer spectroscopy}

${ }^{57} \mathrm{Fe}$ transmission Mössbauer spectroscopy in constant acceleration mode has been used. The source was ${ }^{57} \mathrm{Co}$ in the Cr matrix and the isomer shift was related to $\alpha-\mathrm{Fe}$ standard. All the spectra have been obtained at room temperature.

The spectra have been decomposed under the assumption that the M-type barium hexaferrite was the only product of the technological process. Mössbauer spectrum of M-type barium ferrite is well-known [3] and consists of 5 sextets coming from 5 ferrite magnetic sublattices. Hence one can use such model sub-spectrum fixing the area ratios of given sublattice sextets 


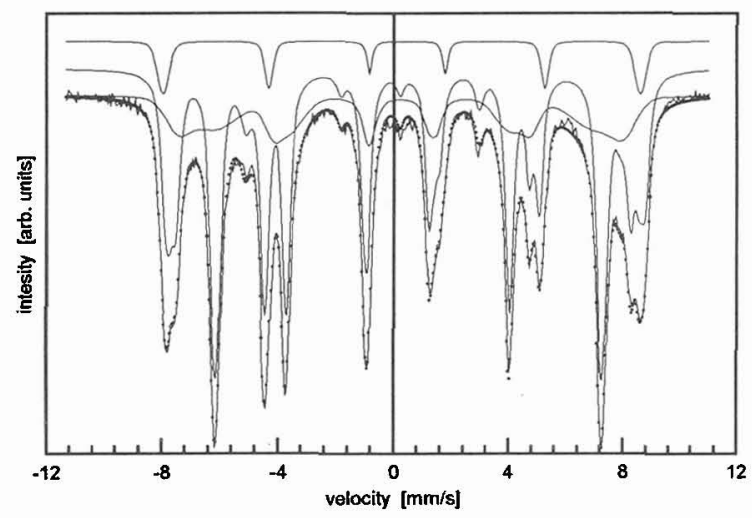

Figure 1: Mössbauer spectrum of a sample annealed at $800^{\circ} \mathrm{C}$ for $1 \mathrm{~h}$ while their hyperfine parameters have been let free. The other component of the composite spectrum corresponding to the unreacted hematite has been represented by one sextet. The first tests of this model have resulted in finding one additional component with characteristics similar to the barium hexaferrite spectrum but with a wider hyperfine field distribution. Such contribution could be ascribed to the early nucleation stages of barium hexaferrite crystals and/or to the perturbed surfaces of the created crystals.

The described fitting procedure has given much better results for the phase analysis than fitting the spectra by a number of uncorrelated sextets with all the parameters let free. The final value of the area ratio of the model components obtained from the fit yields the relative amount of the given iron-containing phase in the sample. The spectrum and its decomposition for a selected sample is shown in Fig. 1.

\section{RESULTS}

Final results of the phase analysis are shown in Fig. 2. One can see an increase of the contribution of the hexaferrite phase with increasing annealing temperature (see bars -a-), while the content of the unreacted hematite decreases. Longer annealing has a positive influence on the formation of the desired ferrite phase as well (compare bars -a- at $700^{\circ} \mathrm{C}$ and - b-). Concerning the series processed by ultrasound, it is obvious that more complete reaction has been achieved (see bars -c-). We believe that the energy of the ultrasound is more localised which leads to much lower content of the perturbed ferrite phase and much more hematite spent by the reaction.

The bars denoted $\sigma$ in Fig. 2. represent saturated specific magnetisation for given sample relative to the value of a pure BaM hexaferrite. These values should correspond to the content of hexaferrite in the given sample. Since the values of magnetisation have been calculated per unit mass of the sample, the results are affected by high content of unreacted hematite and other

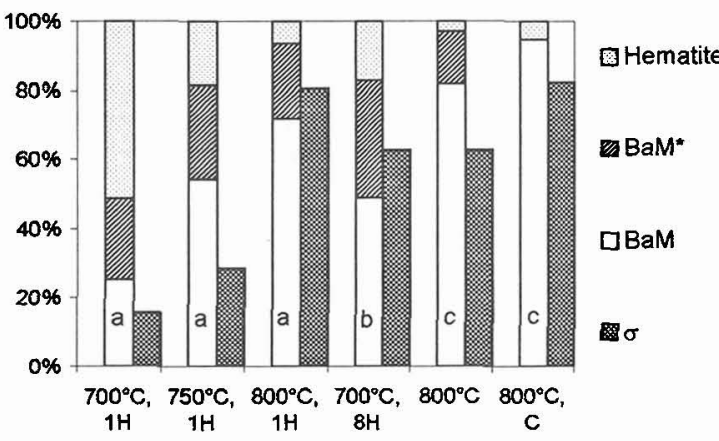

Figure 2: Relative amount of various phases from Mössbauer spectra compared to specific magnetic moments: a - ground in planetary mill and annealed for 1 hour, b-annealed for 8 hours, c - processed by ultrasound nonmagnetic products of the reaction. Although we tried to extract the hexaferrite from the final product, it is difficult to separate it from the unreacted hematite.

\section{CONCLUSIONS}

A modified technological method for preparing powders of single crystalline particles of M-type hexagonal barium ferrites has been used, basing on two traditional ones. This method merges the advantages of the initial ones - technological simplicity of the ceramic method and good particle shape with narrow distribution of the glass-crystallisation technique.

$700{ }^{\circ} \mathrm{C}$ seems to be the beginning of the hexaferrite nucleation. The optimum parameters of the reaction are $800^{\circ} \mathrm{C}$ annealing for 8 hours. Milling by ultrasound brings better results than the classical planetary mill due to better reaction conditions and lower contribution of the perturbed ferrite phase in the final product.

Mössbauer spectroscopy proved to be a good tool for analysing results of similar technological research. It gives more detailed and specific information regarding magnetic properties than some macroscopic methods.

\section{References}

[1] M.H. Kryder: IEEE Trans. Magn. 25 (1989) 4358

[2] T.C. Gibb: J. Mater. Chem. 3 (1993) 441

[3] S. Lego: Ph.D. Thesis, Faculty of Mathematics and Physics, Charles University, 1995, Prague 